\title{
Physiological responses of Quercus suber to the effect of water deficit in presence of ectomycorrhizal fungi
}

\author{
Nasslahsen Bouchra ${ }^{1 *}$, Ouajdi Mohamed ${ }^{2}$, Smouni Abdelaziz ${ }^{3}$, Fahr Mona ${ }^{4}$, Abbas Younes ${ }^{5}$ \\ 1,3,4 Faculty of Sciences, Mohammed V University, Rabat, Morocco \\ ${ }^{2}$ Forest Research Center, Rabat, Morocco \\ ${ }^{5}$ Polyvalent laboratory R\&D, Polydisciplinary Faculty, University of Sultane Moulay Slimane, Beni Mellal, Morocco
}

\section{Keywords}

Ectomycorrhizae

Symbiosis

Drought tolerance

Quercus suber

Maamora

Received: 2 Janury 2018

Accepted: 1 February 2018

Published: 7 February 2018

\begin{abstract}
This study was carried out to assess the response of young cork oak plants inoculated by nine fungal isolates (Russul $s p$. Lactar controversus, Amanita pantherina, Cortinarius sp., Hebeloma sp., Boletus sp., Lactarius volemus, Inocybe $s p$. and Scleroderma sp.) to water deficit. Acorns were used as plant material. They were provided from canton "A" of the Maamora forest, harvested in Decem ber, and soaked in water for 24 hours before planting. As fungal material, 9 species of ectomycorrhizal fungi (Russula sp., Lactarius volemus, Lactarius controversus, Inocybe sp., Scleroderma sp., Amanita pantherina, Cortinarius sp., Hebe loma sp., Boletus sp) have been used for the preparation of the inocula. The results showed that controlled mycorrhization significantly improves plants tolerance to drought stress. Boletus $s p$. was the most efficient isolate that procured to cork oak seedlings a better stomatacal conductance, root and shoot dry weight, and chlorophyll content. Also, the leaf water potential, proline, and anthocyanin accumulation were lower in seedlings with Boletus inoculation. After the drought stress stage, cork oak plants have been rehydrated, and again, Boletus $s p$. produced a mean recovery of $60 \%$ while it was only $1 \%$ in plant control. These data clearly show that the inoculation of cork oak plants with ectomycorrhizal isolates, such as Boletus sp. could be a very interesting pathway in the sandy soils of Maamora and subsequently in determining the success of its regeneration programs.
\end{abstract}

(C) 2018 The Author(s). Published by TAF Publishing.

\section{INTRODUCTION}

Seasonal drought is an important limiting factor for photosynthesis and growth of Mediterranean trees and shrubs. Throughout its geographic range, cork oak is a species suffering from frequent periods of water deficit during the critical first growing season which constitute a crucial step to achieve seedling survival in afforestation and restoration projects through the Mediterranean area [1,2]. The effects of water stress on cork oak plants are numerous. They vary according to the severity and duration of the stress, the stage of development and the genotype [3, 4]. Symptoms of water stress in cork oak include both morphological changes: loss of leaves, drying branches, a reduction in growth in diameter and height that affects other developmental processes, as flowering, fruiting and reproduction [5], and physiological changes, an influence at the cellular level which affects membrane formation and cell division processes; inhibited enzymatic activity and modifications of the biochemical metabolism [6]. Overall, the growth of the cork oak under limiting water supply conditions is strongly disturbed [7]. Alternately, to deal with this problem as shown by many experiments, the use of ectomycorrhizal fungi associated with plants can enhance water use of soil when its availability is reduced [8]. The mycelium networks can play a crucial role in the absorption and transport of water, especially under drought condition $[9,10]$. This allows

\footnotetext{
${ }^{*}$ Corresponding author: Nasslahsen Bouchra

†email: bouchranasslahsen@gmail.com
} 
reducing damages caused by soil shrinking and cracking on roots [8]. In addition, mycorrhizal fungi can improve mineral nutrition and modify the osmotic adjustment in host tree cells resulting from the accumulation of minerals and organic acid [11]. To date, only few studies have been made on the effect of mycorrhizal fungi on oak physiology. The majority of the experiments that have been conducted, used the Pisolithus genus fungi, which is widespread in warm temperate regions around the world and frequently found in cork oak woodland [8]. The adaptation of Pisolithus to soil stresses led to consider it as a candidate for studying the role of mycorrhizae in promoting drought tolerance in cork oak. However many other fungi are well adapted to environmental stresses and are encountered in cork oak ecosystems with marked water deficit. This is the case of the Maamora forest in Morocco, considered as the largest cork oak stand with a sandy substratum. This study was carried out to assess the response of young Quercus suber plants to the combined effect of controlled mycorrhization by using nine fungi isolates: Russula $s p$. Lactarius controversus, Amanita pantherina, Cortinarius sp., Hebeloma sp., Boletus sp., Lactarius volemus, Inocybe sp., Scleroderma $s p$ and a drought stress caused by watering down. The overall goal is to further improve the quality of seedlings grown in forest nurseries to cope with the planting environment conditions where the lack of water arises more acutely.

\section{MATERIAL AND METHODS}

\section{A. Plant Material, Ectomycorrhizal Fungi and Culture Conditions}

Acorns were used as plant material. They were provided from canton "A" of the Maamora forest, harvested in December and soaked in water for 24 hours before planting. As fungal material, 9 species of ectomycorrhizal fungi (Russula $s p$., Lactarius volemus, Lactarius controversus, Inocybe sp., Scleroderma sp., Amanita pantherina, Cortinarius sp., Hebeloma sp., Boletus $s p$ ) have been used for the preparation of the inocula. The culture substrate is composed of $100 \%$ of sterile mud from the Maamora forest inoculated with about $300 \mathrm{~g}$ of crushed carpophore from 9 species of mycorrhizal fungi selected from the Cork oak forest soil, using a sieve of $0.5 \mathrm{~mm}$ diameter while changing gloves and sieving every time the inoculant species are changed. The selected acorns were sown in racks by tilting them onto the culture substrate of about $2 \mathrm{~cm}$ in alveolar plates with a $500 \mathrm{cc}$ volume, 15-cm depth and a 7-cm diameter.

\section{B. Experimental Design}

Watering was applied 3 to 4 times a week, and weeding was practiced to avoid any competition between the cork oak and weeds. A complete irrigation stop carried out the application of the stress after 6 months of culture and applied for four weeks.

\section{Plant Biomass}

Plants were uprooted after the application of the two different water treatments and roots were rinsed with water to eliminate soil particles. For each plant, shoot and length, shoot basal diameter, and total leaf number were recorded. Fresh Weight (FW) of the roots and leaves was recorded directly after excision from the plants. For Dry Weight (DW) determination, a subset of leaves and roots from each plant were dried in an oven at $72^{0} \mathrm{C}$ for $72 \mathrm{~h}$.

\section{Plant Water Status}

The water potential allows the diagnosis of the water status of a plant. Leaf water potential measurements were taken using a "Scholander pressure chamber". The pressure chamber is a closed enclosure for exerting pressure on a plant organ in order to know the pressure of the sap in the vessels of the xylem. Leaf water content was measured by placing the top of the leaf inside a portable "porometre".

\section{E. Stomatal Conductance}

Using the "Decagon porometer forceps" leaf stomatal conductance and leaf temperature measurement was done. The Porometer measures the stomatic conductance of the leaves using the equilibrium state technique. The steady state technique measures the steam pressure and the steam flux of a leaf surface.

\section{F Chlorophyll Measurement}

About $100 \mathrm{mg}$ of fresh leaves were added to $10 \mathrm{ml}$ of solution prepared from $25 \%$ ethanol and $75 \%$ acetone and then stored at $30^{\circ} \mathrm{C}$ in the dark for 48 hours. Then, the optical density of the mixture was measured at two wavelengths: $663 \mathrm{~nm}$ and $645 \mathrm{~nm}$ for chlorophyll a and b respectively. The chlorophyll pigment concentrations are expressed in mg.g-1.FW according to the following formulas:

Chl a: 12.3 DO (663)-0.86 DO (645)/10

Chl b: 9.3 DO (645)-3.6DO (663)/10.

\section{G. Proline Content}

For determination of free proline content, leaf samples were collected during non-stressed state and during severe stress. Proline content was assessed colorimetrically, using 
the protocol of [12] and modified by [13]. $100 \mathrm{mg}$ of plant material were taken and introduced into a test tube supplemented with $2 \mathrm{ml}$ of $40 \%$ methanol. The whole was heated for 1 hour at $85^{\circ} \mathrm{C}$ in a water bath.

$1 \mathrm{ml}$ of extraction solution was removed, then adding to it $1 \mathrm{ml}$ of acetic acid, $25 \mathrm{mg}$ of ninhydrin and $1 \mathrm{ml}$ of a solution containing $12 \mathrm{ml}$ of distilled water, $80 \mathrm{ml}$ of orthophosphoric acid and $30 \mathrm{ml}$ of acetic acid.

After 30 minutes of boiling, $5 \mathrm{ml}$ of toluene was added followed by stirring. The upper phase was then recovered and dehydrated by the addition of anhydrous sodium sulphate. The optical density is then determined at a wave length of $528 \mathrm{~nm}$. The results obtained are reported on the calibration curve: the standard range is obtained by means of a mixture of acetic acid, ninhydrin and ortho-phosphoric acid.

\section{H. Anthocyanin Content}

Samples of leaves stored at $\left(-80^{\circ} \mathrm{C}\right)$ were ground using liquid nitrogen. $15 \mathrm{mg}$ of grounded leaves were added to 1.5 $\mathrm{ml}$ of extraction solution (18\% Propanol, 1\% HCL and 81\% $\mathrm{H}_{2} \mathrm{O}$ ) and incubated at $90^{\circ} \mathrm{C}$ for 3 minutes. The supernatant was then recovered after a centrifugation of 2 minutes at $10000 \mathrm{rpm}$. A spectrometric assay was then carried out at two wavelengths: $535 \mathrm{~nm}$ and $650 \mathrm{~nm}$. The anthocyanin content was then expressed in absorbance (A535-A 650) per mg of fresh material.

\section{Resumption of Seedlings after a Period of Water Stress}

At the end of the experiment and in order to measure the recovery of the Quercus suber plants a daily irrigation of the plants was done.

\section{J. Statistical Analysis}

1) ANOVA variance analysis: The data were analysed using the "SPSS version 24" software. According to the main objective of this study, an analysis of variance was made with "ANOVA two Way" in addition to the Newman and Keuls tests with a threshold of significance set at 0.05 .

2) Multivariate analysis: An additional analysis with the software R allowed the realization of a Principal Component Analysis (PCA).

\section{RESULTS}

After 6 months of culture, all cork oak plants were mycorrhized but the mycorrhization rate varies according to the mycorrhizal isolates (Table 1). Fungi with high root colonization are both "Boletus sp." and "Amanita pantherina" with $40 \%$ and $39 \%$, respectively.

TABLE 1

MYCORRHIZATION RATE OF Q. SUBER PLANTS UNDER NORMAL WATER CONDITIONS

\begin{tabular}{ll}
\hline \hline Russula sp. & $30 \%$ \\
Lactarius controversus & $35 \%$ \\
Amanita pantherina & $40 \%$ \\
Cortinarius $s p$. & $29 \%$ \\
Hebeloma $s p$. & $33 \%$ \\
Boletus $s p$. & $39 \%$ \\
Lactarius volemus & $36 \%$ \\
Inocybe sp. & $28 \%$ \\
Scleroderma sp. & $32 \%$ \\
\hline \hline
\end{tabular}

\section{A. Morphological Response to Drought Stress}

1) Plant height: The average height of the cork oak plants (Figure 1) varies according to the hydric status and the applied fungi treatment reaching a height between $14.98 \mathrm{~cm}$ and $20.5 \mathrm{~cm}$.

According to the S-N-K (Student-Newman-Keuls) test, there were no significant differences between the stressed, and the non-stressed plants inoculated or no by the mycorrhizal fungi.

2) Collar diameter: Statistical analysis showed that the water deficit seems to have no effect on the collar diame- ter of the cork oak plants. No difference was noted between fungi treatment and control (Figure 2).

3) Leaves number: A significant difference in the number of leaves (Figure 3) was observed between young cork oak plants under different water and fungi treatments. Nonstressed plants were able to reach a foliar number of 23.4 under normal conditions, while stressed plants did not reach more than 17 leaves.

Non-stressed plants inoculated by Russula sp. and Scleroderma sp. and stressed inoculated plants by Lactarius controversus a represents the best results with a number of leaves included between 23 and 24 . 


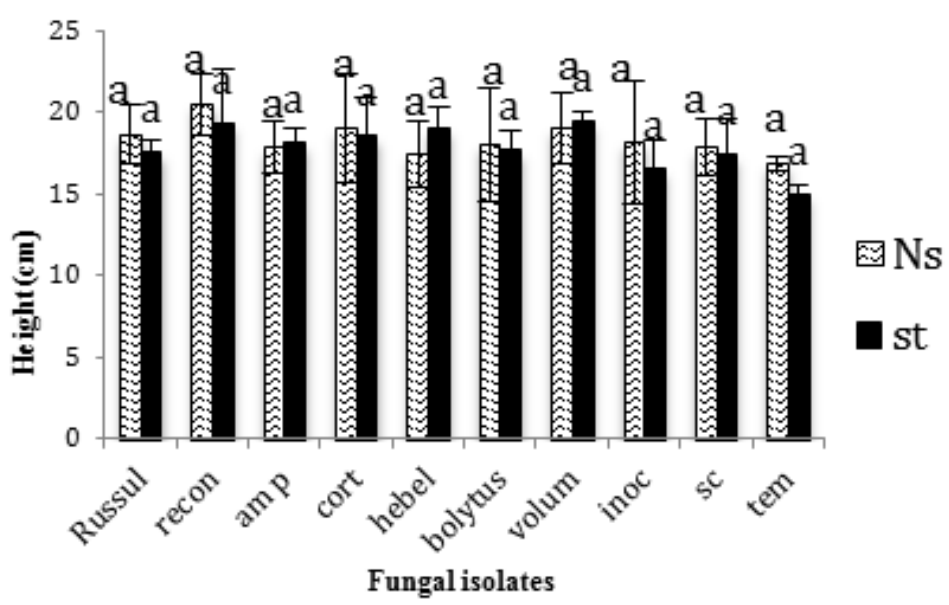

Fig. 1. Average height of cork oak plants inoculated or not with 9 different isolates in normal condition or stress condition. Means followed by different letters have significant differences at the level of $p<0.05$

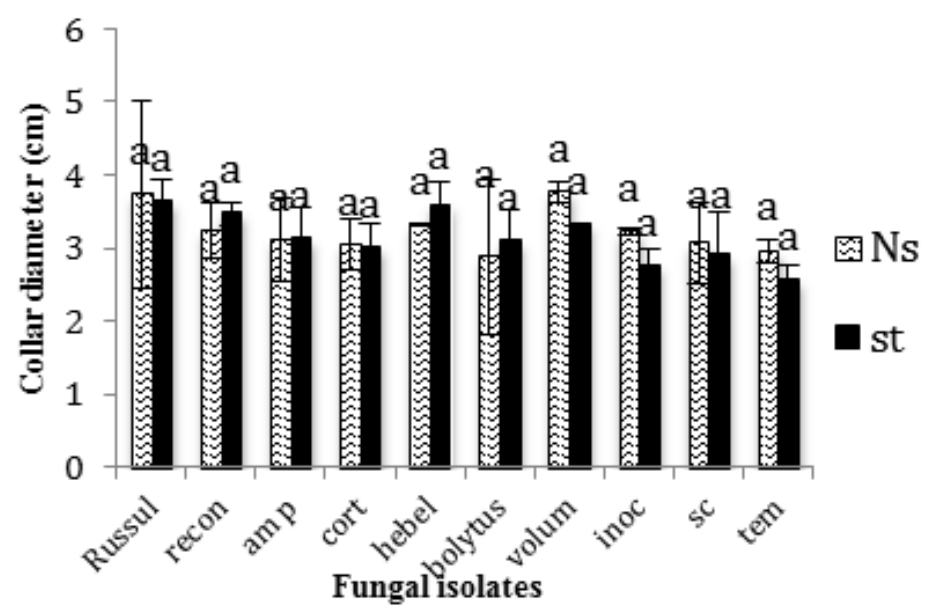

Fig. 2. Collar diameter of cork oak plants inoculated or not with 9 different isolates in normal condition or stress condition. Means followed by different letters have significant differences at the level of $p<0.05$.

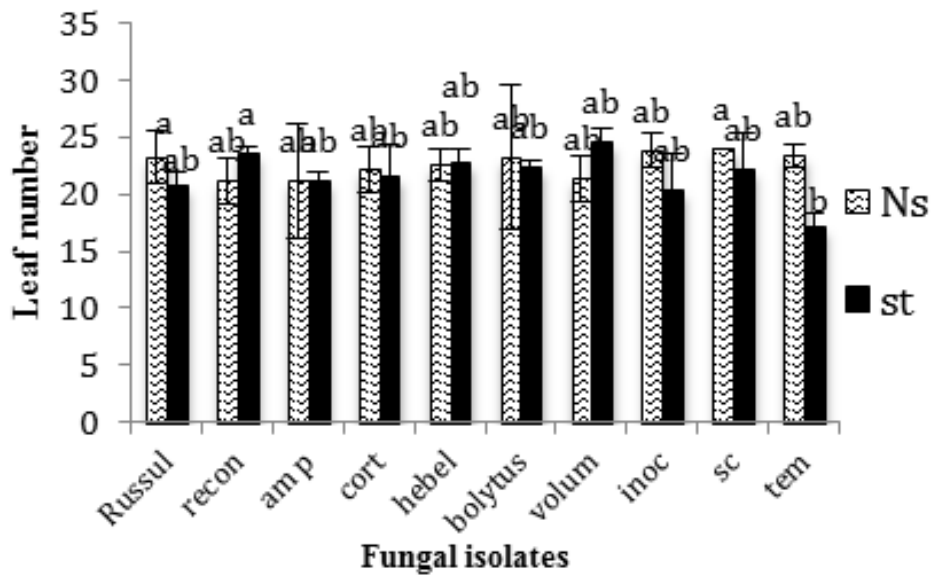

Fig. 3. Leaf number of cork oak plants inoculated or not with 9 different isolates in normal condition or stress condition. Means followed by different letters have significant differences at the level of $p<0.05$ 


\section{B. Plants Biomass}

1) Root development: Significant differences in dry root weight between stressed, non-stressed, inoculated and non-inoculated plants were observed.

The control plants had fairly similar dry weight values under both situations, with a dry weight of $9.1 \mathrm{~g}$ in normal condition and a dry weight of $8.53 \mathrm{~g}$ in stressed condition.

The maximum values resulting in a higher dry root weight are observed in plants inoculated with the fungi treatment
Boletus sp. under water deficient conditions but also in normal water condition with respective values of $16.4 \mathrm{~g}$ and $12.61 \mathrm{~g}$, followed by plants inoculated with Amanita pantherina and under these conditions of water stress with a dry root weight of $12.46 \mathrm{~g}$.

The lowest values resulting in a low dry root weight were observed in the stressed control plants and the plants inoculated with Lactarius volemus under stress conditions with respective values of $8.53 \mathrm{~g}$ and $9.69 \mathrm{~g}$.

TABLE 2

ROOTS DRY WEIGHT OF CORK OAK PLANTS

\begin{tabular}{lllll}
\hline \hline & \multicolumn{3}{c}{ Roots Dry Weight } \\
\hline \multirow{2}{*}{ Treatment } & Drought Stressed & \multicolumn{2}{l}{ Well Watered } \\
\cline { 2 - 5 } & $\mathrm{Av}$ & St.de & $\mathrm{Av}$ & St.de \\
\hline Russula & $11.57 \mathrm{c}$ & 0.06 & $10.28 \mathrm{ef}$ & 0,26 \\
Lactarius controversus & $10.2 \mathrm{efg}$ & 0.17 & $9.03 \mathrm{i}$ & 0.058 \\
Amanita pantherina & $12.46 \mathrm{~b}$ & 0.45 & $9.73 \mathrm{gh}$ & 0.20 \\
Cortinarius $s p$. & $10.65 \mathrm{de}$ & 0.08 & $10.16 \mathrm{efg}$ & 0.06 \\
Hebeloma sp. & $10.79 \mathrm{~d}$ & 0.08 & $10.31 \mathrm{ef}$ & 0.01 \\
Boletus sp. & $16.4 \mathrm{a}$ & 0.43 & $12.61 \mathrm{~b}$ & 0.023 \\
Lactarius volemus & $9.69 \mathrm{gh}$ & 0.20 & $9.26 \mathrm{hi}$ & 0.25 \\
Inocybe sp. & $10.09 \mathrm{fg}$ & 0.09 & $9.65 \mathrm{gh}$ & 0.15 \\
Scleroderma sp. & $11.33 \mathrm{c}$ & 0.49 & $9.65 \mathrm{gh}$ & 0.15 \\
Control & $8.53 \mathrm{j}$ & 0.05 & $9.1 \mathrm{i}$ & 0.17 \\
\hline \hline
\end{tabular}

2) Shoot development: Significant differences in shoot dry weight between stressed, unstressed, inoculated and noninoculated plants are observed.

The best results are observed in inoculated non-stressed plants. Maximum aerial dry weight values are recorded in plants inoculated with Boletus sp., even in conditions of wa- ter deficit with an aerial dry weight of $14.36 \mathrm{~g}$ compared with only 15.53 in normal water condition.

The lowest values were observed in the control (noninoculated) plants under normal and stress conditions with values of $9.41 \mathrm{~g}$ and $7.65 \mathrm{~g}$ respectively.

TABLE 3

ROOTS DRY WEIGHT OF CORK OAK PLANTS

\begin{tabular}{lllll}
\hline \hline & \multicolumn{3}{c}{ Roots Dry Weight } \\
\hline \multirow{2}{*}{ TTT } & \multicolumn{2}{l}{ Drought } & Stressed & \multicolumn{2}{l}{ Well Watered } \\
\cline { 2 - 5 } Russula & $\mathrm{Av}$ & St.de & $\mathrm{Av}$ & St.de \\
Lactarius controversus & $12.5 \mathrm{e}$ & 0.1 & $13.6 \mathrm{~d}$ & 0.15 \\
Amanita pantherina & $13.41 \mathrm{~d}$ & 0.20 & $12.54 \mathrm{e}$ & 0.13 \\
Cortinarius sp. & $12.41 \mathrm{e}$ & 0.16 & $14.6 \mathrm{bc}$ & 0.1 \\
Hebeloma sp. & $12.26 \mathrm{e}$ & 0.37 & $14.85 \mathrm{~b}$ & 0.14 \\
Boletus sp. & $14.36 \mathrm{bc}$ & 0.23 & $14.58 \mathrm{bc}$ & 0.07 \\
Lactariusvolemus & $12.33 \mathrm{e}$ & 0.15 & $15.53 \mathrm{a}$ & 0.47 \\
Inocybe sp. & $11.63 \mathrm{f}$ & 0.05 & $14.79 \mathrm{~b}$ & 0.16 \\
Scleroderma $s p$. & $10.93 \mathrm{~g}$ & 0.12 & $14.59 \mathrm{bc}$ & 0.16 \\
Control & $7.65 \mathrm{i}$ & 0.05 & $14.14 \mathrm{c}$ & 0.12 \\
\hline \hline
\end{tabular}




\section{Physiological and Biochemical Response to Drought Stress}

1) Plants water status: 1.1) Relative humidity: Significant differences in relative humidity between stressed, non-stressed, inoculated and non-inoculated plants are observed. The non-mycorrhized plants showed a low relative humidity percentage that did not exceed $34 \%$ under normal water conditions and drought stress situations.

An improvement due to the fungi treatment is noted. The inoculated and non-stressed plants had a higher relative hu- midity, between $61.3 \%$ and 53\%. The stressed and inoculated plants by the fungi Amanita pantherina were able to maintain a percentage of relative humidity of $58.96 \%$; equal to the non-stressed plants. The plants inoculated with the fungi Boletus sp. were also able to maintain a higher relative humidity with a value of $44 \%$, higher than that of the young cork oak plants under normal conditions.

The fungi treatment Lactarius volemus remains the weakest since the relative humidity of plants stressed and inoculated by this fungus did not exceed $26.3 \%$.

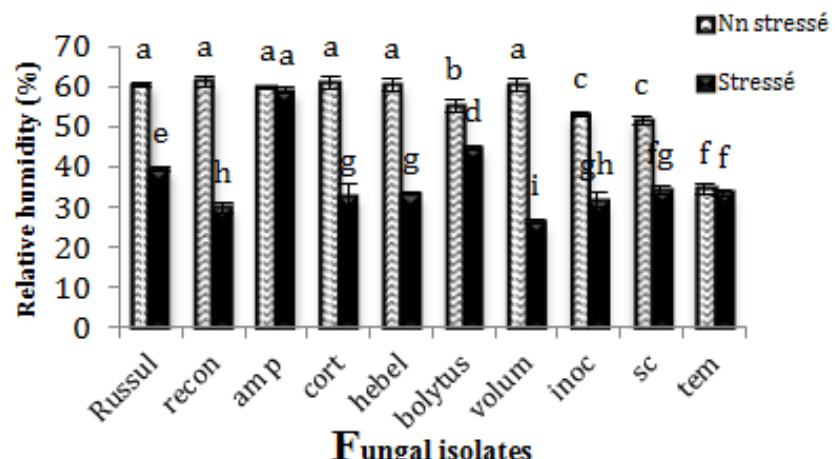

Fig. 4. Relative humidity of cork oak plants inoculated or not with 9 different isolates in normal condition or stress condition. Means followed by different letters have significant differences at the level of $p<0.05$

1.2) Water potential: Significant differences in water potential between stressed, non-stressed, mycorrhized and non-mycorrhized plants are observed. Control plants (noninoculated) have the higher water potential values under both conditions; stressed and non-stressed with -74 bar and $-20,33$ bar respectively. In the non-stressed condition, the fungi treatment that allowed obtaining the lower water potential is Cortinarius sp. with -10 bar value, whereas with the "Amanita" fungi, the highest value is shown reaching -26 bar. Under stress conditions, high water potential values are observed in plants inoculated with the fungi Inocybe sp. with -53.66 bar, while the minimum values are obtained by inoculating the plants with the fungi Boletus sp. with -28 bar.

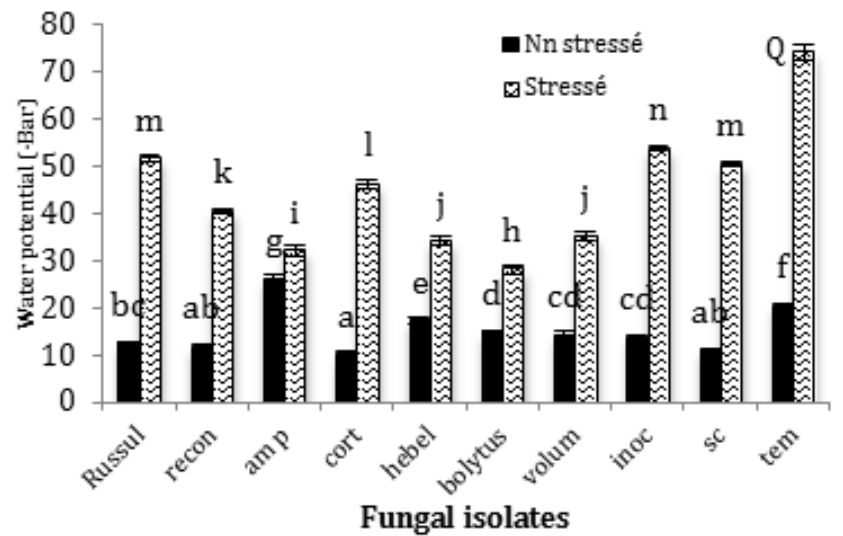

Fig. 5. Water potential of cork oak plants inoculated or not with 9 different isolates in normal condition or stress condition. Means followed by different letters have significant differences at the level of $p<0.05$. 
2) Chlorophyll: Significant differences in chlorophyll content in all characters were observed.

The non-mycorrhized well-watered plants and nonmycorrhized under drought stress plants showed the lowest values of chlorophyll content with only a $3.45 \mathrm{mg} . \mathrm{g}-1 \mathrm{FW}$. For mycorrhized and non-stressed plants, their total chlorophyll content differed from one fungal treatment to another; the highest numbers are observed in plants inoculated with the fungi Russul with a chlorophyll content of 23.45mg.g-1FW, whereas the minimum values are observed in plants inoculated with the fungi Lactarius controversus with a value of chlorophyll content of $15.81 \mathrm{mg} . \mathrm{g}-1 \mathrm{FW}$. For plants under drought stress, the highest chlorophyll content is shown in plants inoculated with the fungi "Boletus" with a value of $21.53 \mathrm{mg}$-1MF, thus giving it higher chlorophyll content than the majority of non-stressed and mycorrhized plants. Plants inoculated with the fungi Hebeloma had the lowest value of chlorophyll content with only 6 mg.-1 MF.
The total chlorophyll content, in normal water conditions, is increased by the mycorrhiza presence. Thus in drought stress conditions the mycorrhization has an important compensating effect.

The fungi Russul offers the best treatment for nonstressed plants with a value of chlorophyll content of $23.45 \mathrm{mg}$.g.-1MF compared to control non-stressed and non-inoculated plants which had only 17.26 mg.g.-1MF. Under the effect of drought, a decrease in total chlorophyll content is noticed; this decrease can be related to enzymatic degradation of chlorophyll due to stomatal closure and low water availability.

The fungi Boletus was the best treatment for drought stressed plants with a value of chlorophyll content of 21.53 mg.g.-1MF, a higher value than both: the plants under normal water conditions with only 21.53 mg.g.1MF of chlorophyll and the control drought stressed plants with only a chlorophyll content value of 3.45 mg.g.-1MF.

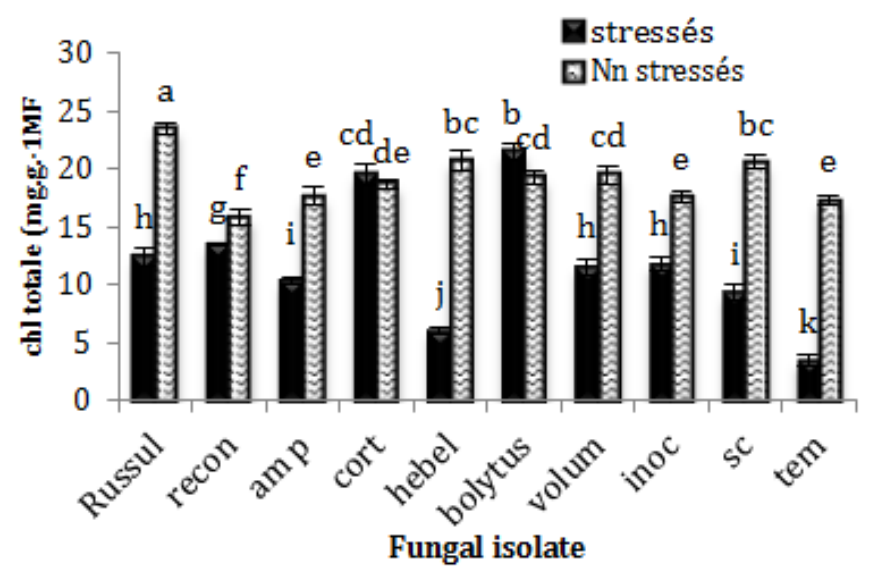

Fig. 6. Total chlorophyll of cork oak plants inoculated or not with 9 different isolates in normal condition or stress condition. Means followed by different letters have significant differences at the level of $p<0.05$.

3) Stomatal conductance: Stomatal conductance is considered an indicator of foliar transpiration rate, and a parameter of the plant water status. A significant difference of stomatal conductance is observed in cork oak plants under different water and fungi treatments. Non-stressed plants showed the maximum values of stomatal conductance; while the drought stressed plants have the minimum ones. For the non-mycorrhized control plants, two values are displayed: 125.3 mmol.m- .s-1 for watered plants and
$62.2 \mathrm{mmol.m}-\mathrm{s}-1$ for plants under drought stress. In the drought stressed plants mycorrhized by the fungi Boletus $s p$., the effect of water stress was not very marked since the stomatal conductance is 125.5 mmol.m-.s- 1 almost identical to that of a non-stressed and non-mycorrhized plant which is $125.3 \mathrm{mmol} / \mathrm{ml}$, while for watered nonmycorrhized plants treatment, the stomatal conductance is only $62.2 \mathrm{mmol} / \mathrm{ml}$. The fungal genus Volumus gave us the lowest value of $36.75 \mathrm{mmol} / \mathrm{ml}$ in water deficit. 


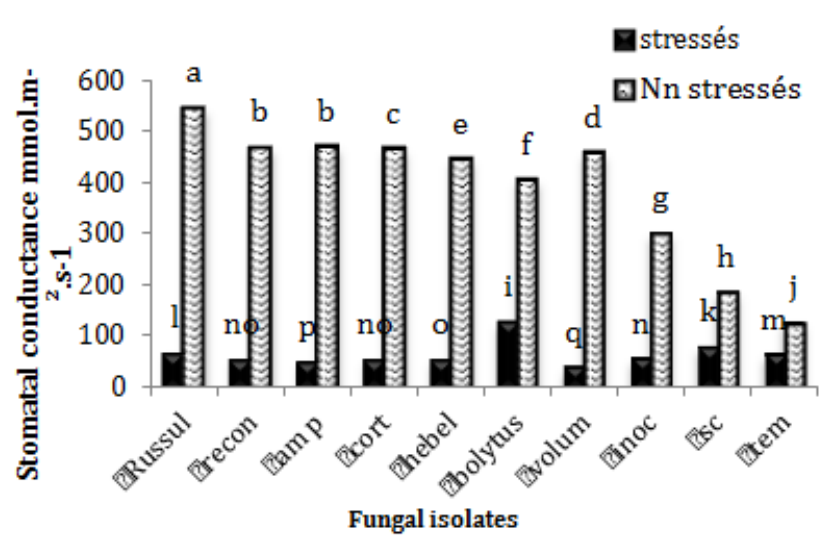

Fig. 7. TStomatal conductance of cork oak plants inoculated or not with 9 different isolates in normal condition or stress condition. Means followed by different letters have significant differences at the level of $p<0.05$

4) Proline: Significant differences in proline content between stressed, non-stressed, inoculated and noninoculated plants were observed. The non-inoculated control plants have a proline content value of $1 \mu \mathrm{mol} \mathrm{mg} \mathrm{MF} \mathrm{in}$ normal water condition and a value of $1.71 \mu \mathrm{mol} / \mathrm{mg} \mathrm{MF}$ in drought stress condition.The plants producing the lowest content of proline are those mycorrhized by fungi Boletus in both watering treatments: stressed and non-stressed with respective values of $0.95 \mu \mathrm{mol} / \mathrm{mg} \mathrm{MF}$ and $0.71 \mu \mathrm{mol} / \mathrm{Mg}$ MF. The plants with a relatively high proline content are those mycorrhized by the fungi Cortinarius sp. and Hebeloma $s p$. under drought conditions with respective values of $2.49 \mu \mathrm{mol} / \mathrm{mg} \mathrm{MF}$ and $2.4 \mu \mathrm{mol} / \mathrm{mg} \mathrm{MF}$, and for normal watering conditions with respective values of $2.1 \mu \mathrm{mol} / \mathrm{mg}$ MF and $1.93 \mu \mathrm{mol} / \mathrm{mg} \mathrm{MF}$.

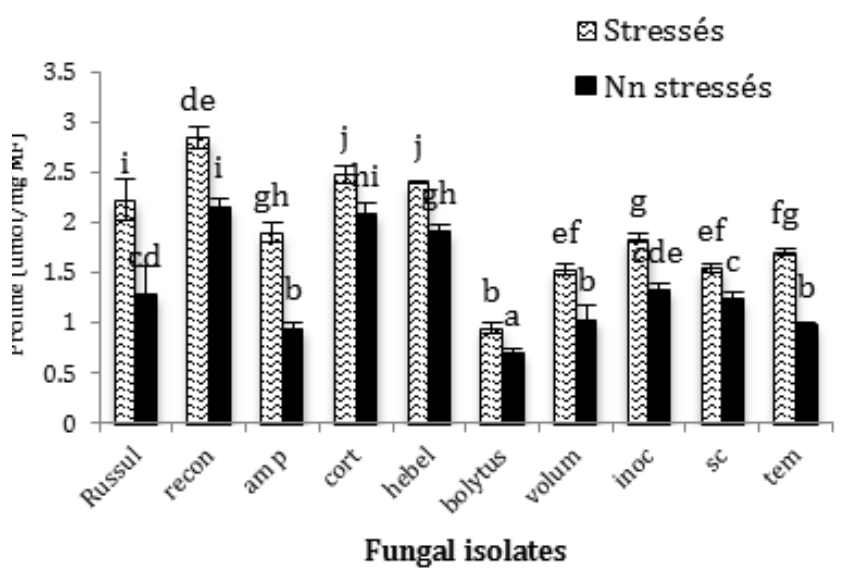

Fig. 8. Proline of cork oak plants inoculated or not with 9 different isolates in normal condition or stress condition. Means followed by different letters have significant differences at the level of $p<0.05$.

5) Anthocyanin: Significant differences in anthocyanin content between stressed, non-stressed, mycorrhized and non-mycorrhized plants are observed. For the noninoculated control plants, an accumulation of $7.33 \mathrm{mg} / 1 \mathrm{in}$ normal water condition and $67.33 \mathrm{mg} / 1$ in stressed condition is showed. The best results with low anthocyanin ac- cumulation were observed in plants mycorrhized by fungi Boletus sp. under normal conditions with a content value of $7.23 \mathrm{mg} / 1$ and under drought stressed conditions with a content value of $35.33 \mathrm{mg} / 1$.Strong accumulation of anthocyanin was noticed in control plants non-mycorrhized under drought condition with a content value of $67.33 \mathrm{mg} / 1$. 


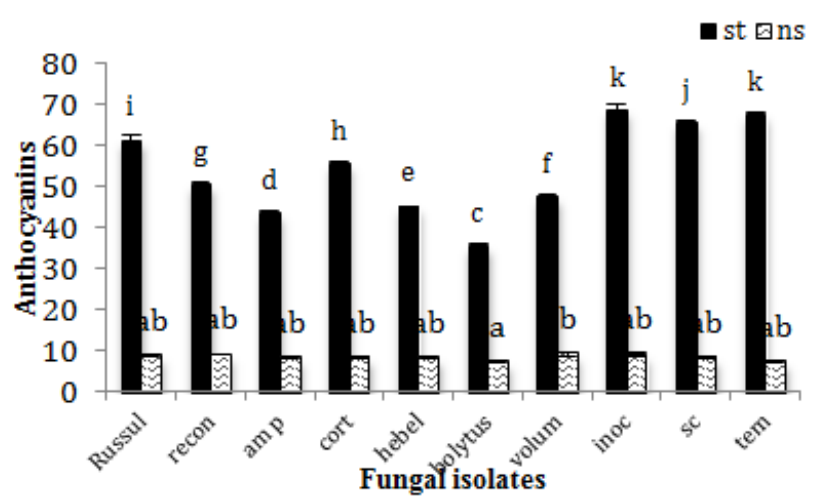

Fig. 9. Anthocyanins of cork oak plants inoculated or not with 9 different isolates in normal condition or stress condition. Means followed by different letters have significant differences at the level of $p<0.05$

\section{The Global Effect of Mycorrhization and Drought Stress on Cork Oak Plants}

The most important factors accounting for Dim 2 (mycorrhized plants) are water potential and Proline. Their effects are in the opposite direction. "Nombre de feuilles" (Leaves number), "diameter au collet" (Collar diameter) and "hau- teur" (Height) are not affected by water treatment or fungal treatment. "Poids sec" (Dry root) has an intermediate value in both treatment conditions. Many factors contribute to Dim1 (non-mycorrhized plants), including "Humd rel"(relative humidity) "poids sec aerien"(Dry shoot), Chlorophyll and "Cond stom"(stomatal conductance).

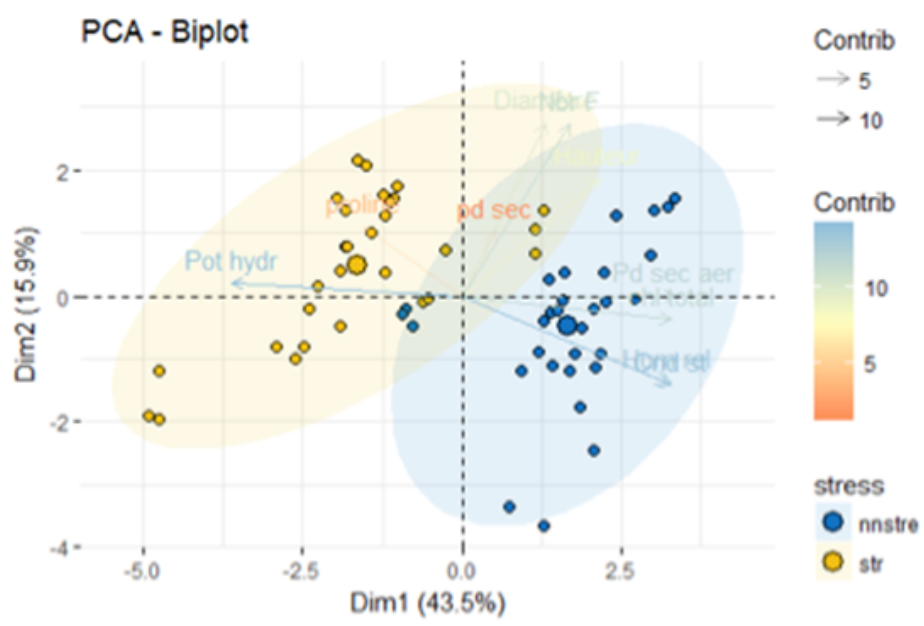

Fig. 10. Complex example by groups (str: drought stressed plants, nnstre: non drought stressed plants) and variables (Dim2: Mycorrhized plants, Dim1: Non-mycorrhized plants) by their contributions to the principal components

\section{E. Quercus Suber Plants Recovery after Drought Stress Period}

After the drought stress period, a recovery of the plants following rewatering was observed; this recovery is influenced by the fungal inoculation, since in the absence of fungi treatment "Control plants" only $1 \%$ of the plants had taken back their normal activities versus $10 \%$ to $60 \%$ for mycorrhized plants.

The better percentage of recovery was observed in plants inoculated with Boletus sp. This fungus treatment ensured better plants recovery with $60 \%$ value while Scleroderma $s p$. and Inocybe sp. were the less effective treatments with only $10 \%$ of recovered plants. 


\begin{tabular}{ll}
\hline \hline Russula sp. & $34 \%$ \\
Lactarius controversus & $23 \%$ \\
Amanita pantherina & $25 \%$ \\
Cortinarius sp. & $20 \%$ \\
Hebeloma sp. & $30 \%$ \\
Boletus sp. & $60 \%$ \\
Lactarius volemus & $22 \%$ \\
Inocybe sp. & $10 \%$ \\
Scleroderma sp. & $10 \%$ \\
Control & $1 \%$ \\
\hline \hline
\end{tabular}

\section{DISCUSSION}

\section{A. Mycorrhization of Quercus Suber Plants}

The noticed differences in Quercus Suber inoculation may be reflected in the presence or absence of factors favouring the development of mycorrhizal fungi [14] Depending on the mycorrhizal species, some changes in cultivation practices such as crop support, soil conditions, phytosanitary treatment and fertilization are required.

During inoculation, good colonization results depend in particular on the quality of the mycorrhizal inoculum used and the dose of inoculum used in order to guarantee the mycorhization of plants $[9,15]$.

\section{B. Morphological Response to Drought Stress}

In terms of height growth and the collar diameter of cork oak, the non-significant differences can be due to the young age of the plants that do not exceed six months but also to the short period of the stress application. The same results were observed one month including both the study of the influence of mycorrhization and the soil type on the growth of Impatiens balsamina plants, where the absence of significant difference related to the presence of mycorrhizae was observed, the differences were only due to the type of soil $[9,16]$. Also, in another study, on beech plants, non-significant differences of height due to mycorrhization [17] and non-significant differences in collar diameter between mycorrhizal and non-mycorrhizal plants were obtained [18]. The small differences in leaves number can be due to the short period of the stress application, which is only four weeks, and the repercussion has not yet been able to be shown on the morphological characters [18].

\section{Plants Biomass (Root and Shoot)}

All plants under stress and no matter what the ectomycorrhizal fungus used completed a fairly extensive root development, which was confirmed by Smith and Read in 2010 [19] and suggests that ectomycorrhizal plants gener- ally have a root system showing, a dry mass higher than that of the roots of non-mycorrhizal plants because the root represents the organ concretizing the association between a host plant and a mycorrhizal fungus. Thus mycelium occupying the root lives in an environment balanced by the homeostasis of the plant. Moreover, according to the bibliography, several works confirm that cork oak is a tree which, from its young age, is more involved in deep rooting in search of water indispensable for its growth, a fact confirmed during this in which the dry root weight of inoculated stressed plants far exceeds the dry root weight of the inoculated, non stressed plants when the dry weight of the plants is taken after stress. The fungus Boletus yielded the best result with a value of $16 \mathrm{~g}$, a result in perfect concordance with that in which inoculation by "Boletus edulis" researchers resulted in a higher root activity than that of the control [20].

For the shoots, in mycorrhizal conditions, mycorrhization may cause a reduction in growth $[18,21]$. It has also been demonstrated that a latency period allowing an inoculated fungus to settle can reduce the initial growth gain of the host relative to non-inoculated ones.

\section{Physiological and Biochemical Response to Drought Stress}

1) Plants water status (water potential, relative humidity): For relative humidity, the ectomycorrhizal fungus could potentially facilitate water supply. Several studies have shown that mycorrhization can increase host resistance to drought stress and improve by improving his mineral nutrition $[22,23]$. The water potential of a plant is considered as an important physiological parameter to describe the water transfer and the hydraulic conductivity of the "soil-plant" system, thus reflecting the ratio of the flux flowing through the plant; it is therefore an overall measure of the efficiency of the conductive system formed by the structure "soil-mycelium-mantle-root-conductive tissues of the 
plant". From the literature, the cork oak has several mechanisms for adjusting its water potential, despite the change in external conditions $[9,19]$.

Ectomycorrhizal fungi are intimately associated with plant tissues at the roots, contributing indirectly to this regulation by modifying the mineral uptake of the tree or its hormonal balance [19]. The presence of a fungal mantle with absorbent roots protects the root system from drying out, either by slowing down the diffusion of the water coming out of the mycorrhiza (this being in agreement with the stronger hydraulic resistance mentioned above) or by constituting a reserve of water [24].

Another characteristic of ectomycorrhizae that influences their contribution to tree water supply are two closely related characteristics according to [25]: the ability to survive and the ability to infect roots even in drought conditions. However, the symbiosis does not decrease the resistance to water transfer to the tree, but increases it.

2) Chlorophyll: Mekkaoui, with a study on the effect of drought stress combined to the use of arbuscular mycorrhization on the plum tree in 2015 [26], the changes in the biochemical behaviour of the tree were noticed. The chlorophyll content in plants under drought stress and mycorrhized was higher than the non mycorrhized ones. The gain for the host is not mandatory since $20 \%$, according to [27], of the production of photosynthesis products are used to preserve and maintain the symbiosis.

For example, [28] found that seedlings colonized by Rhizopogon vinicolor AH Smith showed higher chlorophyll and photosynthesis contents and a higher biomass production than the non-mycorrhized seedlings.

3) Stomatal conductance: The fungi inoculum, and independently of water nutrition conditions, can influence stomatal conductance $[22,23]$. Research of Dosskey et al. In 1991 confirms this; during a drying cycle; they interpret the observed phenomena in the absence of nutritional effects and direct effect of the fungi on water absorption and stomatal conductance by a correlation with the proportion of the fixed carbon that is exported to the fungi [29]. Excess carbon demand by the fungi stimulates photosynthesis and therefore the stomata respond by opening, independently of stomatal regulation due to drought stress [30].

4) Proline: When drought stress is applied, the increase in proline content is directly observed, which has been demonstrated by several studies on many species. It appears that during periods of stress, proline can give plants a tolerance to drought by setting up an antioxidant system that would have the role of indicating a cellular osmotic adjustment [31,32]. This could be explained by an accentua- tion of biochemical signals during a drought stress by mycorrhizal hyphae. For plants mycorrhized by the fungi Boletus, a decrease in the proline content values is noticed, probably due to the main role of the fungus of roviding all necessary elements to the plant so it wont feel being on a drought situation and not obliged to accumulate a large amount of proline, this is explained, according to Garbaye in 2013 study, to the fact that the ectomycorrhizae fungi Boletus are a part of "early stage" fungal species [33].

5) Anthocyanin: Water stress seems to induce anthocyanin biosynthesis since the highest concentrations were observed in drought stressed plants. According to Besson and his team in 2014, anthocyanin is acting as a protective and antioxidant, but for the plants inoculated by the fungi Boletus the opposite is observed, the anthocyanin content decreased with only a $35.33 \mathrm{mg} / 1$ value; the best result obtained for drought stressed plants, which is in perfect concordance with the proline contents results obtained previously [34].

\section{E. Quercus Suber Plants Recovery from Drought Stress Period}

Culture conditions that may influence the development of mycorrhizal fungi may interfere with the prophylactic potential of mycorrhizae, whether abiotic factors such as drought, temperature, or biotic factors [8]. As shown in the table above, the fungi Boletus $s p$. is one of the ectomycorrhiza with the highest rate of recovery after drought stress, thus explaining good physiological phenology of the plants inoculated by this type of fungi.

This important development of the fungi Boletus, even under water stress conditions, was confirmed by a study carried out in 1989 by Coleman and his team where they examined the ability to tolerate an imposed drought stress of 55 isolates of ectomycorrhizal fungi belonging to 18 species, since with increase of drought Boletus edulis was the only fungus that had the ability of growing even in water potential up to -3 MPa [35].

\section{CONCLUSION AND RECOMMENDATIONS}

The worst phenomenon of all ecosystems is "Drought", which is considered to be a trigger for forest decline [36]. At a plant level, a lack of water induces multiple reactions related to its metabolism. Thus, a mycorrhizal symbiosis between ectomycorrhizal fungi and plant roots would induce modifications at both functional and structural level allowing a good tolerance to water deficit by the plant [19]. In our study, a comparison of both morphological and physiological changes of the cork oak, inoculated or non- 
inoculated, under drought condition was carried out in order to evaluate the effect of the ectomycorrhizal symbiosis on drought tolerance of Quercus suber plants, by using nine mycorrhizal genuses: Russul, Reconverse, Boletus, Amanita, Cortinaire, Hebelome, Volumus, Inocib or Scleroderme, naturally growing in cork oak forest: "Maamora forest" in Morocco.

Our study showed that non-inoculated cork oak plants do not tolerate drought stress, which has resulted physiologically by an accumulation of proline and anthocyanin, loss of chlorophyll in addition to a very high water potential. On the other hand, the use of ectomycorrhizal fungi signif- icantly improves the efficiency of water use under drought stress conditions.

The results obtained in this experiment indicated that a good tolerance of the cork oak plants to the drought stress was shown when the plants were inoculated by Boletus. This genus of ectomycorrhizal fungi could have the ability to quickly create a merge relation with the roots of cork oak plants, increase their root absorption area providing to the plants a better hydration and nutrition. This fungus may be recommended in plant production programs applicable at least for plantations in Maamora area.

\section{REFERENCES}

[1] L. Gómez-Aparicio, R. Zamora, J. M. Gómez, J. A. Hódar, J. Castro, and E. Baraza, “Applying plant facilitation to forest restoration: A meta-analysis of the use of shrubs as nurse plants," Ecological Applications, vol. 14, no. 4, pp. 1128-1138, 2004. doi: 10.1890/03-5084

[2] P. Bunruk, D. Kantachote and A. Sukhoom, "Isolation and selection of purple non-sulfur bacteria for phosphate removal in rearing water from shrimp cultivation," Journal of Applied and Physical Sciences, vol. 3, no. 2, pp. 73-80, 2017. doi: 10.20474/japs-3.2.5

[3] S. C. Grossnickle, "Importance of root growth in overcoming planting stress," New Forests, vol. 30, no. 2-3, pp. 273-294, 2005. doi: $10.1007 / s 11056-004-8303-2$

[4] S. Sung, J. Lim, S. Palikhe., K. Han, and S. Kim, "'Development of the system form for concrete casting in the girder bridge slab-purlin hanging system," Journal of Advances in Technology and Engineering Research, vol. 2, no. 2, pp. 18-21, 2016. doi: 10.20474/-jater2.1.4

[5] T. Kozlowski, "Carbohydrate sources and sinks in woody plants," The Botanical Review, vol. 58, no. 2, pp. 107-222, 1992. doi: $10.1007 /$ bf02858600

[6] M. Farooq, A. Wahid, N. Kobayashi, D. Fujita, and S. Basra, "Plant drought stress: Effects, mechanisms and management," in Proceedings of International Conference on Sustainable Agriculture. New York, NY: Springer, 2009.

[7] T. Obata, S. Witt, J. Lisec, N. Palacios-Rojas, I. Florez-Sarasa, J. L. Araus, J. E. Cairns, S. Yousfi, and A. R. Fernie, “Metabolite profiles of maize leaves in drought, heat and combined stress field trials reveal the relationship between metabolism and grain yield," Plant Physiology, vol. 3, no. 4, pp. 11-64, 2015. doi: 10.1104/pp.15.01164

[8] J. F. Gomes, Cork Oak Woodlands on the Edge. New York, NY: Taylor \& Francis, 2010.

[9] T. R. Horton, Mycorrhizal Networks. Dordrecht, Netherlands: Springer, 2015.

[10] A. H. Plamboeck, T. E. Dawson, L. M. Egerton-Warburton, M. North, T. D. Bruns, and J. I. Querejeta, "Water transfer via ectomycorrhizal fungal hyphae to conifer seedlings," Mycorrhiza, vol. 17, no. 5, pp. 439-447, 2007. doi: 10.1007/ s00572-007-0119-4

[11] M. Chalot, A. Javelle, D. Blaudez, R. Lambilliote, R. Cooke, H. Sentenac, D. Wipf, and B. Botton, “An update on nutrient transport processes in ectomycorrhizas," in Proeedings of International Conference on Diversity and Integration in Mycorrhizas, California, CA, 2002.

[12] W. Troll and J. Lindsley, "A photometric method for the determination of proline," Journal of Biological Chemistry, vol. 215, no. 2, pp. 655-660, 1955. doi: 10.1021/ac60105a039

[13] P. Monneveux and M. Nemmar, “Contribution à l'étude de la résistance à la sécheresse chez le blé tendre (triticum aestivum l.) et chez le blé dur (triticum durum desf.): Étude de l'accumulation de la proline au cours du cycle de développement,' Agronomie, vol. 6, no. 6, pp. 583-590, 1986. doi: 10.1051/agro:19860611

[14] J.-F. Briat and D. Job, Les sols et la vie souterraine: Des enjeux majeurs en agroécologie. Versailles, Yvelines: Quae, 2017.

[15] R. Duponnois, S. Wahbi, H. Sanguin, L. Ouahmane, M. Hafidi, and Y. Prin, "Les associations mycorhiziennes dans les sols: Pour une meilleure maitrise de la production vegetale," Soils and Underground Life: Major Issues in Agri-Ecology, vol. 2, no. 3, pp. 223-235, 2017. doi: 10.4000/books.irdeditions.3304 
[16] M. Leye, D. Macoumba, F. Ndiaye, D. Bassirou, D. H. Maiguizo, and D. Tahir, “Effet de la mycorhization et de la salinité sur la croissance, les réponses biochimiques et la productivité de jatropha curcas l., cultivée sous serre," International Journal of Biological and Chemical Sciences, vol. 6, no. 4, pp. 1741-1760, 2012. doi: 10.4314/ijbcs.v6i4.30

[17] J. Garbaye, "Premiers résultats de recherches sur la compétitivité des champignons ectomycorhiziens," Plant and Soil, vol. 71, no. 1-3, pp. 303-308, 1983. doi: 10.4314/ijbcs.v6i4.30

[18] D. M. Orcutt, The Physiology of Plants Under Stress: Soil and Biotic Factors. New York, NY: John Wiley \& Sons, 2000.

[19] S. E. Smith and D. J. Read, Mycorrhizal Symbiosis. Cambridge, MA: Academic press, 2010.

[20] M. Wu, W. Zhang, C. Ma, and J. Zhou, "Changes in morphological, physiological, and biochemical responses to different levels of drought stress in chinese cork oak (quercus variabilis bl.) seedlings," Russian Journal of Plant Physiology, vol. 60, no. 5, pp. 681-692, 2013. doi: 10.1134/s1021443713030151

[21] J. V. Colpaert and I. Verstuyft, "The ingestad concept in ectomycorrhizal research: Possibilities and limitations," Physiologia Plantarum, vol. 105, no. 2, pp. 233-238, 1999. doi: 10.1034/j.1399-3054.1999.105207.x

[22] M. S. Lamhamedi, P. Y. Bernier, and J. André-Fortin, "Hydraulic conductance and soil water potential at the soil root interface of pinus pinaster seedlings inoculated with different dikaryons of pisolithus sp." Tree Physiology, vol. 10, no. 3, pp. 231-244, 1992. doi: 10.1093/treephys/10.3.231

[23] R. M. Augé, "Water relations, drought and vesicular-arbuscular mycorrhizal symbiosis," Mycorrhiza, vol. 11, no. 1, pp. 3-42, 2001. doi: 10.1093/treephys/10.3.231

[24] R. Agerer, "Exploration types of ectomycorrhizae," Mycorrhiza, vol. 11, no. 2, pp. 107-114, 2001. doi: 10.1007/ s005720100108

[25] M. H. Neves Machado, "La mycorhization contrôlée d'eucalyptus globulus au portugal et l'effet de la sécheresse sur la symbiose ectomycorhizienne chez cette essence," Ph.D. dissertation, Henri Poincare University, Nancy, France, 1995.

[26] K. Mekkaoui, "Effet du stress hydrique et la mycorhization arbusculaire sur le comportement biochimique du prunier," n.d. [Online]. Available: https://goo.gl/CCSSja

[27] I. Jakobsen and L. Rosendahl, "Carbon flow into soil and external hyphae from roots of mycorrhizal cucumber plants," New Phytologist, vol. 115, no. 1, pp. 77-83, 1990. doi: 10.1111/j.1469-8137.1990.tb00924.x

[28] M. Dosskey, R. Linderman, and L. Boersma, “Carbon sink stimulation of photosynthesis in douglas fir seedlings by some ectomycorrhizas," New Phytologist, vol. 115, no. 2, pp. 269-274, 1990. doi: 10.1111/j.1469-8137.1990.tb00452.x

[29] M. Dosskey, L. Boersma, and R. Linderman, "Role for the photosynthate demand of ectomycorrhizas in the response of douglas fir seedlings to drying soil," New Phytologist, vol. 117, no. 2, pp. 327-334, 1991. doi: 10.1111/j.1469-8137. 1991.tb04914.x

[30] G. Wang, D. Coleman, D. Freckman, M. Dyer, S. McNaughton, M. Agra, and J. Goeschl, "Carbon partitioning patterns of mycorrhizal versus non-mycorrhizal plants: Real-time dynamic measurements using $11 \mathrm{CO}_{2}$," New Phytologist, vol. 112, no. 4, pp. 489-493, 1989. doi: 10.1111/j.1469-8137.1989.tb00342.x

[31] M. Yamada, H. Morishita, K. Urano, N. Shiozaki, K. Yamaguchi-Shinozaki, K. Shinozaki, and Y. Yoshiba, "Effects of free proline accumulation in petunias under drought stress," Journal of Experimental Botany, vol. 56, no. 417, pp. 1975-1981, 2005. doi: $10.1093 / \mathrm{jxb} / \mathrm{eri195}$

[32] M. Ashraf and M. Foolad, "Roles of glycine betaine and proline in improving plant abiotic stress resistance," Environmental and Experimental Botany, vol. 59, no. 2, pp. 206-216, 2007. doi: 10.1016/j.envexpbot.2005.12.006

[33] J. Garbaye, La Symbiose Mycorhizienne: Une Association Entre Les Plantes Et Les Champignons. Versailles, Yvelines: Editions Quae, 2013.

[34] C. K. Besson, R. Lobo-do Vale, M. L. Rodrigues, P. Almeida, A. Herd, O. M. Grant, T. S. David, M. Schmidt, D. Otieno, T. F. Keenan et al., "Cork oak physiological responses to manipulated water availability in a mediterranean woodland," Agricultural and Forest Meteorology, vol. 184, pp. 230-242, 2014.

[35] M. D. Coleman, C. S. Bledsoe, and W. Lopushinsky, "Pure culture response of ectomycorrhizal fungi to imposed water stress," Canadian Journal of Botany, vol. 67, no. 1, pp. 29-39, 1989. doi: 10.1139/b89-005

[36] J. C. Linares and J. J. Camarero, "From pattern to process: Linking intrinsic water-use efficiency to drought-induced forest decline," Global Change Biology, vol. 18, no. 3, pp. 1000-1015, 2012. doi: 10.1111/j.1365-2486.2011.02566.x 